\title{
POLÍTICA PÚBLICA E REFORMA AGRÁRIA: UMA ANÁLISE DOS PRINCIPAIS INDICADORES DA POLÍTICA DE ASSENTAMENTOS RURAIS
}

\author{
Cléria Figueredo* \\ Christian Luiz da Silva**
}

\begin{abstract}
Resumo
O presente artigo, apresenta resultados dos principais indicadores da Política de Reforma Agrária, desde a sua implementação na década de 1970 até 2017. A metodologia adotada foi o estudo de caso, com o levantamento dos dados dos imóveis rurais obtidos para fins de criação de Projetos de Assentamento, Famílias Assentadas e de Supervisão Ocupacional desses projetos. Os resultados mostram que a cada mudança de governo, a agenda política para criação e assentamento de famílias sofre altos e baixos, bem como apontam para a necessidade de novas pesquisas que deem conta de avaliar se os objetivos da Política de Reforma Agrária atingiram àqueles estabelecidos na legislação que a regulamenta e legitima esta política desde sua implementação.
\end{abstract}

Palavras-chave: Política Pública. Reforma Agrária. Indicadores. Projetos de Assentamento.

\footnotetext{
* Mestranda do curso de Planejamento e Governança Pública da Universidade Tecnológica Federal do Paraná - UTFPR. E-mail:kakakode@gmail.com.

** Pós-doutor em Administração, pela Universidade de São Paulo (USP). Professor do mestrado em Planejamento e Governança Pública e do mestrado e doutorado em Desenvolvimento Regional da Universidade Tecnológica Federal do Paraná - UTFPR, bolsista produtividade do CNPq. E-mail:christiansilva@utfpr.edu.br.
} 


\section{Introdução}

Para a implantação da política de Assentamento de Famílias nos Projetos de Assentamento Rurais da Reforma Agrária, são necessárias várias etapas, que vão desde a obtenção do imóvel, seleção e homologação das famílias, o desenvolvimento do projeto que inclui a implantação de infraestrutura básica, crédito, demarcação topográfica/ georreferenciamento e assistência técnica, para então titular, consolidar e emancipar (INCRA, 2018a).

A essência da Política de Reforma Agrária é a implantação dos Projetos de Assentamento (PA's), que ocorre, por meio e tão somente via obtenção de imóveis. Sem os imóveis, o Instituto Nacional de Colonização e Reforma Agrária (INCRA), não consegue criar projetos e assentar famílias.

Como toda a política, a Reforma Agrária foi criada e legitimada por meio de lei, com a edição nos anos 1960 da lei de Reforma Agrária, qual seja, a Lei. N.4.504, de 30 de novembro de 1964 (Estatuto da Terra). Sua implementação ocorreu por caua das pressões das ligas camponesas e trabalhadores sem-terra.

Essa é uma política setorial sob a responsabilidade do INCRA, a qual tem permitido o acesso à terra a centenas de trabalhadores rurais sem-terra, via a obtenção de terras, criando um campo de reprodução econômico e social, por meio da criação e implantação e desenvolvimento dos PA's. Além disso, o INCRA cuida da execução de ações estruturantes, como o apoio a financiamentos, a assistência técnica, a infraestrutura básica, ao fomento a agroindústria, a comercialização dos produtos produzidos pelos assentados, ou seja, fomenta as atividades que possam favorecer a sustentabilidade dessas unidades em busca da melhoria da qualidade de vida dessas famílias, que não será o foco do presente estudo.

Os PA's são um produto da ação política de Reforma Agrária, e estão submetidos aos efeitos da gestão institucional (leis, diretrizes, normas, etc.) do INCRA, que é a autarquia responsável pelo provimento e apoio necessário à sua viabilização. Vale destacar que, o governo central muda o curso das ações, por meio da distribuição de orçamento para execução das ações, de acordo com as prioridades dadas a cada nova gestão, sem nenhum ou pouco planejamento e isso afeta sensivelmente o andamento dessa política.

Sendo assim, o presente estudo tem como objetivo apresentar os principais indicadores da política de assentamentos de famílias a fim de demonstrar como uma agenda política pode mudar o curso de uma política pública, bem como fazer um resgate teórico das teorias referentes às Políticas Públicas, construído a partir das referências estudadas na Disciplina de Política e Sustentabilidade, autores como Frey (2000), Dye (2011), Kraft e 
Furlong (2010), Silva (2012), dentre outros, assim como lançando mão dos Relatórios de Gestão do INCRA e de documentos oficiais de controle que a instituição vem utilizando para o monitoramento dessa política.

Este artigo encontra-se dividido em quatro seções, além desta introdução. A segunda seção trata da fundamentação teórica necessária para a construção do artigo. Depois, são abordados os aspectos metodológicos da pesquisa. A seguir, são apresentados os resultados obtidos, e o trabalho é, por fim, finalizado com a seção que traz a conclusão da pesquisa.

\section{Fundamentação Teórica}

\section{Políticas Públicas}

Falar de Políticas Públicas é falar da vida de uma sociedade, de um Estado, de um governo. A implementação de uma política pública é um processo muito complexo. De acordo com Dye (2011, p.1), "Política Pública é qualquer coisa que os governos escolhem fazer ou não fazer”. $\mathrm{O}$ autor ainda diz que o estudo das Políticas Públicas é importante porque não atinge somente a Política Pública em si, mas as suas causas e efeitos, o impacto que ela provoca numa sociedade, e seu escopo econômico.

Para Souza (2006, p. 24), a Política Pública não tem só um conceito, e cita alguns autores como Mead (1995), "[...] a define como um campo dentro do estudo da política que analisa o governo à luz de grandes questões públicas", e Peters (1980), o qual diz que "Política pública é a soma das atividades dos governos, que agem diretamente ou através de delegação, e que influenciam a vida dos cidadãos". E ainda, afirma que é de Laswell, a definição mais conhecida, "Decisões e análises sobre política pública implicam responder as seguintes questões: quem ganha o quê, por quê e que diferença faz".

Souza (2006), preconiza que mesmo que uma política seja formulada por pressão coletiva, implantá-la ou não é decisão de governo. Entendese, portanto, que ela está diretamente relacionada ao Estado. E de acordo com Silva (2012), o Estado sendo uma organização política, administrativa e jurídica, é permanente nesse processo, estruturado a partir de governos transitórios e responsáveis em gerir a coisa pública.

Para Silva (2012, p.18), “[...] independente do autor, todas as definições apontam para os governos, onde as ideias são concebidas e as decisões tomadas”. Porém, o governo não é o único ator para que uma Política Pública seja criada e implantada. Associações, Organizações Não Governamentais (ONG's), instituições públicas e privadas, dentre outras, são agentes importantes para a criação e implementação de uma Política Pública. 
Heidman (2009, p. 31), acrescenta que o "Terceiro setor é o nome dado hoje ao esforço de produção do bem público por agentes não governamentais, mas ao mesmo tempo distinto do setor empresarial de mercado". Ou seja, a constituição de uma Política Pública acontece por meio de grupos de interesse ligados ao problema que se quer resolver, sendo sua participação atrelada a cada realidade social, e a cada momento histórico.

De acordo com Dye (2011), a formulação de uma política se dá, a partir da identificação de um problema - configuração de agenda formulação - legitimação - implementação e avaliação. Tal configuração também está apresentada por Silva (2012, p. 23) no Quadro 1 a seguir:

\section{Quadro 1 - Processo da política pública}

\begin{tabular}{|c|c|c|}
\hline Processo político & Descrição genérica da etapa & Participantes \\
\hline Identificação de problema & $\begin{array}{l}\text { Identificação dos problemas políticos por } \\
\text { meio da demanda de individuos e grupos de } \\
\text { ação governamental }\end{array}$ & $\begin{array}{l}\text { Instituições formais e informais (responsáeis } \\
\text { por identificar o problema por pressões sociais, } \\
\text { econômicas, políticas, ambientais ou culturais) }\end{array}$ \\
\hline Agenda dos agentes & $\begin{array}{l}\text { Atenção da mídia e nos órgãoes públicos } \\
\text { oficiais sobre problemas públicos especificos } \\
\text { para definir o que será decidido }\end{array}$ & $\begin{array}{l}\text { Instiuições formais e informais } \\
\text { (responsáveis por discutir o problema e } \\
\text { apresentar demandas ao governo) }\end{array}$ \\
\hline Formulação de políticas & $\begin{array}{l}\text { Desenvolvimento de propostas de políticas } \\
\text { pelo interesse de grupos. }\end{array}$ & $\begin{array}{l}\text { Instituiçoes formais, informais e o governo (a } \\
\text { responsabilidade é compartilhada, mas dependendo } \\
\text { do arranjo institucional existente, um deles será } \\
\text { o responsável por consolidar a formulação da } \\
\text { política). }\end{array}$ \\
\hline Legitimação da política & $\begin{array}{l}\text { Definição da ação e política como sendo } \\
\text { oficial, tornando-a lei. }\end{array}$ & $\begin{array}{l}\text { Governo (responsabilidade tipica do governo que } \\
\text { garante a legitimidade da política). }\end{array}$ \\
\hline $\begin{array}{l}\text { Implementação de } \\
\text { políticas }\end{array}$ & $\begin{array}{c}\text { Implementação da política pelas burocracias, } \\
\text { gastos públicos, regulações e outras } \\
\text { atividades fins. }\end{array}$ & $\begin{array}{c}\text { Governo e instituições formais, informais } \\
\text { (a responsabilidade é comparitlhada, mas } \\
\text { normalmente é coordenada pelo governo. Em } \\
\text { alguns casos é exclusivamente implementada pelo } \\
\text { governo). }\end{array}$ \\
\hline Avaliação de políticas & $\begin{array}{c}\text { Avaliação continuada da política pública } \\
\text { tanto em termos de processo quanto de } \\
\text { resultado }\end{array}$ & $\begin{array}{l}\text { Governo e instituições formais, informais (a } \\
\text { responsabilidade é compartilhada, mas o governo } \\
\text { necessariamente deve avaliar a sua política. As } \\
\text { instituiçoes formais e infomais, quando bem } \\
\text { estruturadas e atuantes, sempre como uma espécie } \\
\text { de auditoria dos resultadsos e grupo de pressão } \\
\text { para melhoria das ações com intuito de não } \\
\text { desvirtuar dos objetivos definidos pela política). }\end{array}$ \\
\hline
\end{tabular}

Fonte: SILVA, (2012, p.23).

Como se observa no quadro, a elaboração de uma Política Pública parte de um problema que surge com a pressão de grupos atingidos por esse problema. Esse processo de elaboração é retratado como ciclo de Políticas Públicas.

Sobre os ciclos de uma política, Frey (2000, p. 226), diz que ele ocorre "Devido ao fato de que as redes e as arenas das políticas setoriais, podem sofrer modificações no decorrer dos processos de elaboração e 
implementação das políticas". Isso é o que ocorre com a política de Reforma Agrária, em várias fases, afetada pelo o que o autor chama de "[...] agir público em fases parciais do processo político-administrativo de resolução de problemas, o 'policy cicle"'.

Segundo Frey (2000), nessas várias fases ocorre uma sequência de elementos do processo político-administrativo que pode ser verificada quanto à esfera de poder, grupos políticos e sociais e às práticas administrativas de cada fase.

A forma como as agendas são definidas, de acordo com Souza (2006), é quando se assume o que fazer com o problema, focalizando o problema, a política em si e seus participantes. “[...] A política pública envolve processos subsequentes após sua decisão e proposição, ou seja, implica também implementação, execução e avaliação.” (SOUZA, 2006, p. 36).

Ainda sobre a policy cicle, no resgate realizado por Gelinski e Seibel (2008), apresenta alguns modelos de Políticas Públicas, (garbage can ou lata do lixo, coalizão de defesa, arenas sociais, equilíbrio interrompido e os modelos influenciados pelo "novo gerencialismo público), sendo o que mais se aproxima a Reforma Agrária no Brasil, é o modelo de "Equilíbrio interrompido" ou "pontuado" (Punctuated Equilibrium), que segundo Gelinski e Seibel (2008, p. 231 apud SOUZA, 2007, p. 77), "Nele, a política pública se caracteriza, [...] por longos períodos de estabilidade, interrompidos por períodos de instabilidade, que geram mudanças nas políticas anteriores”. De acordo com Gelinski e Seibel (2008), esse modelo tem papel importante para a construção de uma imagem da Política Pública proposta (policy image), bem como do enquadramento institucional que opera nesse processo de elaboração da imagem.

E quanto à análise e avaliação de uma Política Pública deve ser realizada então pelo conjunto de atores envolvidos, estatais, sociais, para poder saber como ela está se comportando na atualidade, bem como o que poderá ocorrer com ela no futuro, e o que e como avaliar.

De acordo com Kraft e Furlong(2010, p. 9), "Uma política pública não é feita a esmo. É afetada por condições sociais e econômicas, prevalecendo valores políticos e o ambiente público do momento, a estrutura do governo, e as normas culturais nacionais e locais, entre outras variáveis".

Apesar de ser considerada uma política de responsabilidade de Estado, a Reforma Agrária, em face de sua natureza conflituosa, de tempos em tempos é ativada ou desativada na pauta política dos governos.

$\mathrm{Na}$ fase da avaliação de políticas e da correção de ação ('evaluation'), apreciam-se os programas já implementados no tocante a seus impactos efetivos. Trata-se de indagar os déficits de impacto e os efeitos colaterais indesejados para poder deduzir consequências para ações e programas futuros. A avaliação ou controle de impacto 
pode, no caso de os objetivos do programa terem sido alcançados, levar ou à suspensão ou ao fim do ciclo político, ou, caso contrário, à iniciação de um novo ciclo, ou seja, a uma nova fase de percepção e definição e à elaboração de um novo programa político ou à modificação do programa anterior. Com isso, a fase da avaliação é imprescindível para o desenvolvimento e a adaptação contínua das formas e instrumentos de ação pública, o que Prittwitz denominou como "aprendizagem política" - (Prittwitz, 1994, p. 60) (FREY, 2010, p.228).

Cabe ao INCRA, avaliar o processo todo dessa política, desde a sua implantação, como deveria ser executada, como foi executada, onde estão os gargalos que impactaram nos resultados, assim como nos problemas que enfrenta junto aos Órgãos de Controle em especial na determinação do Tribunal de Contas da União (TCU), que recentemente fez paralisar ações do órgão com a publicação do Acórdão 775/2016, que afetou diretamente as famílias assentadas, deixando-as sem acesso a financiamentos, à documentação, etc. Corrigindo o fluxo das ações e programas até então executados, a fim de dar andamento sem desvirtuar dos objetivos definidos para essa política.

Como avaliar? De que forma podemos avaliar uma política tão complexa como a Reforma Agrária? Inicialmente, podemos analisar então, os principais indicadores que podem mostrar o que ocorreu em termos numéricos, quantos imóveis foram obtidos, quantos assentamentos foram criados, quantas famílias foram beneficiadas com o acesso a terra e analisar o comportamento desses no tempo e no espaço.

Alguns estudiosos dizem que "Não existe consenso quanto ao que seja avaliação de políticas públicas, pois o conceito admite múltiplas definições, algumas delas contraditórias" (TREVISAN, 2008, p.535), e isso se explica em razão desta perpassar por diversas e variadas disciplinas, instituições e executores, com grande abrangência.

Para Ala-Harja e Helgason (2000) apud Trevisan (2008), a avaliação compreende, analisar os resultados de um programa em relação aos objetivos propostos. "A avaliação é determinar a pertinência e alcance dos objetivos, a eficiência, efetividade, impacto e sustentabilidade do desenvolvimento" (TREVISAN, 2008, p.536).

E ainda, Trevisan (2008), afirma que a avaliação de uma política, pode ser um problema para os governantes e gerentes, pois seu resultado poderá causar constrangimentos públicos, seus resultados podem ser utilizados pelo público com intuito de criticá-lo, ou vice-versa.

Realizar uma avaliação, não significa que as informações produzidas serão utilizadas (TREVISAN, 2008), além disso, o autor aponta para quatro tipos de uso da avaliação: instrumental, conceitual, instrumento de persuasão e esclarecimento. Não importa o tipo, o importante é atingir o 
interessado final que é o público envolvido e a sociedade. Logo, o uso dos indicadores criados e monitorados pelo INCRA, deve demonstrar o quanto cresceu ou não, o público de trabalhadores sem-terra até os dias atuais, como se comportaram esses indicadores com as mudanças no governo.

Quanto à utilização do uso de indicadores para análise de uma política pública, Januzzi (2002), ensina que para avaliar uma Política Pública são necessários indicadores de diferentes naturezas.

Um indicador social é uma medida em geral quantitativa, dotada de significado social substantivo, usado para substituir, quantificar ou operacionalizar um conceito social abstrato, de interesse teórico (para pesquisa acadêmica) ou programático (para a formulação de políticas). É um recurso metodológico, empiricamente referido, que informa algo sobre um aspecto da realidade social ou sobre mudanças que estão ocorrendo na mesma. Os indicadores sociais se prestam a subsidiar as atividades de planejamento público e formulação de políticas sociais nas diferentes esferas de governo, possibilitam o monitoramento, por parte do poder público e da sociedade civil, das condições de vida e bem-estar da população e permitem o aprofundamento da investigação acadêmica sobre a mudança social e os determinantes dos diferentes fenômenos sociais [...] (JANUZZI, 2002, p. 55).

Como orienta o autor, um indicador serve para medir, informar algo sobre uma determinada situação, atividade. Numericamente, é capaz de demonstrar se os objetivos e/ou meta de uma política estão sendo atingidas. Pode ou não ser capaz de dar respostas qualitativas. Indicadores servem para o monitoramento, o controle e planejamento de uma ação dentro de uma Política Pública.

\section{Políticas de Assentamentos Rurais}

A essência da Política de Reforma Agrária é a Política de Assentamentos Rurais. O termo assentamento, segundo Fabrini (2000, p.67) "[...] surgiu no interior do Estado e refere-se às ações que têm por fim ordenar ou reordenar recursos fundiários com alocações de populações para solução de problemas socioeconômicos [...]”.

Há uma diferença entre projetos de colonização que foram criados em terras devolutas transcritas em nome da União Federal no período de 1985 a 1989, com a política de criação de Projetos de Assentamentos, por meio de desapropriação, compra e venda, etc., que traz para o campo áreas realmente reformadas.

São distintas, portanto, as maneiras de obtenção de terras, com a utilização preferencialmente da desapropriação por interesse social para a política de Reforma Agrária, bem como são diversos os níveis de 
participação e decisão. Nos projetos de colonização o governo distribui terras devolutas, nos projetos de assentamentos, apesar de ser o Estado o responsável por obter os imóveis rurais, o resultado vem por meio de pressão dos movimentos sociais.

"Os assentamentos de reforma agrária, são conquistas alcançadas pela organização e mobilização dos trabalhadores envolvidos.” (FABRINI, 2000, p. 68). Ou seja, ela aconteceu no Brasil, tão somente pela força dos movimentos sociais que ocuparam terras e obrigaram uma ação governamental e forçosamente provocaram a obtenção de imóveis para a criação de assentamentos de famílias.

E o resultado dessa luta, pode ser verificado no Gráfico 1 a seguir, o qual apresenta os imóveis obtidos por decretos presidenciais, entre o início da Política de Reforma Agrária até o governo do Presidente Michel Temer (1985-2017).

Gráfico 1 - Imóveis Obtidos por Decretos Presidenciais - 1985-2017

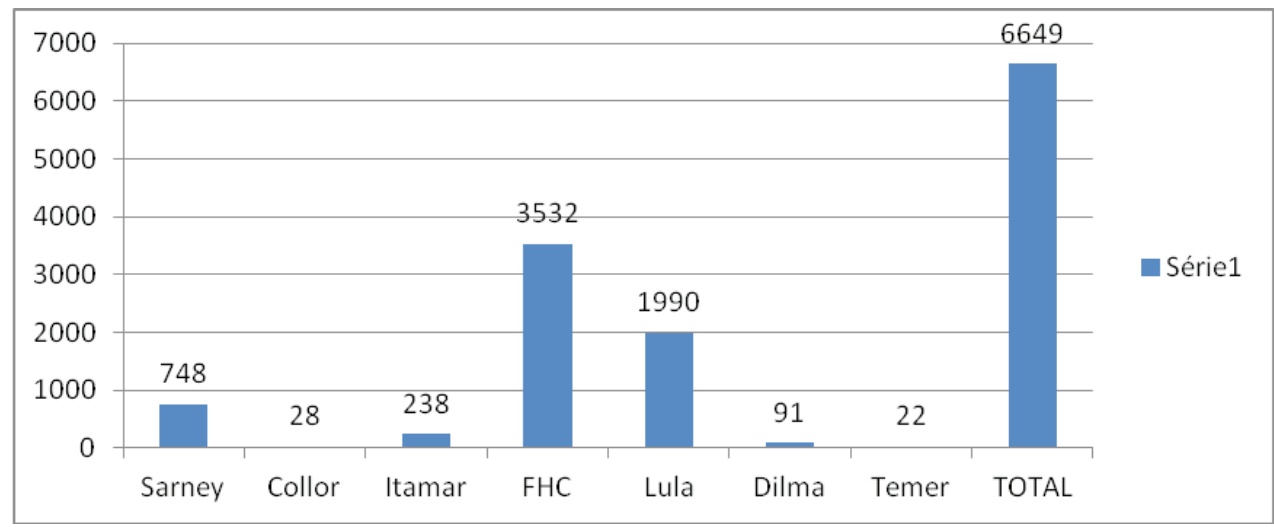

Fonte: INCRA (2018c) e FOCA BRASIL (2018).

Pode-se perceber com esses resultados, como se comportou a Política de Reforma Agrária em várias fases políticas do Brasil. Para entender melhor, é necessário um estudo em conjunto com as mudanças na política brasileira nesse período, que arenas se formaram, como se comportaram os atores envolvidos, etc., é preciso ser realizada análise dos acontecimentos, e avaliação dos impactos que essa política vem causando nos objetivos traçados.

Quando consultados estudos realizados sobre a história da criação de alguns Projetos de Assentamentos, o que se verifica é que ela é oriunda de muita luta dos movimentos sociais, pois primeiro vem ocupação da área, a criação do acampamento e depois um grande período de espera, a criação do assentamento. Destaque-se a narração de Moreira (2013, p.148) de como ocorreu a criação do Projeto de Assentamento Ireno Alves dos Santos no Município de Rio Bonito do Iguaçu/PR, 
Com pouco mais de uma década de sua fundação o MST promove uma ação ousada: a ocupação do maior latifúndio do estado do Paraná, com área total aproximada em 86 mil hectares, alcançando o território parcial de quatro municípios da região centro-sul e sudoeste. Pertencente ao grupo Giacometti Marodin também proprietário de uma madeireira localizada neste mesmo espaço. Para levar a diante uma ação com proporções o Movimento organiza esta que seria a maior ocupação até então realizada: 03 mil famílias ocupam a área na madrugada do dia 17 de abril de 1996, conformando 12 mil pessoas em marcha. A ação é resultado de alguns anos de planejamento interno e dá articulação com organizações parceiras como sindicatos de trabalhadores rurais, partidos, segmentos de Igrejas, entre outros.

Como também, no estudo realizado por Moura (2006, p.62) na criação do Projeto de Assentamento Santa Maria localizado no Município de Paranacity/PR,

Já no final da década de 1980, grupos de famílias organizados pelo MST, provenientes das ocupações de terras nas regiões de maior conflito no Estado e/ou que não conseguiram ser assentados, migraram para a região Noroeste e se uniram aos grupos ali existentes. O primeiro acampamento na Microrregião de Paranavaí foi do município de Querência do Norte, demorou sete anos para se tornar assentamento, mas após seis anos dessa primeira ocupação, o MST conquista, em 1994, o Assentamento Santa Maria localizado no município de Paranacity.

Mais um exemplo é narrado no estudo de Tsukamoto e Asari (2003, p. 490) que envolveu a criação de três assentamentos rurais denominados Cruz de Malta, Dorcelina Folador e Florestan Fernandes localizados, em Tamarana, Arapongas e Florestópolis, respectivamente,

No caso de Tamarana, o processo de ocupação e territorialização das terras pelo MST foi intenso nesses últimos 15 anos e hoje, conta com 10 assentamentos e 268 famílias implantadas em solos pouco férteis e com declividade acentuada. A baixa fertilidade dos solos, distante da sede do município $(30 \mathrm{~km})$, transporte precário com ausência de linhas de ônibus regulares para a cidade, são alguns elementos que depreciam o preço da terra. A pecuária é a atividade predominante com a forte presença de grandes propriedades rurais. Esses fatores propiciaram o processo de ocupação pelos integrantes do MST e, as negociações ocorreram sem conflitos entre as partes sob a intermediação do INCRA. Há que se observar que todos os assentamentos precederam de uma fase de ocupação, com inúmeras famílias acampadas a espera da negociação e posterior distribuição de lotes.

Em todas as referências levantadas para este estudo, os autores são unânimes em afirmar que a Reforma Agrária no Brasil, ocorreu sobre forte pressão dos movimentos sociais. Em todo o acompanhamento realizado 
dentro do INCRA, não se consegue visualizar uma ação própria do órgão, em fiscalizar uma área e colocá-la à disposição para a criação de um Projeto de Assentamento, que não tenha origem na pressão dos movimentos sociais por ocupação ou ameaça de ocupação. Isso demonstra que a reforma agrária aconteceu, não por vontade absoluta do Estado brasileiro, mas por uma forte pressão dos movimentos sociais, na maioria das vezes com grandes conflitos e até mortes no campo.

A política de Assentamentos Rurais tem, portanto, uma história de luta de famílias que buscam conquistar seu espaço no campo, para produção de seu sustento.

Porém, é importante destacar, que a Política de Assentamentos Rurais, não é só isso. Monte (2013) dedicou um capítulo de sua tese de doutorado para estudar a natureza e as características dessa política, e ainda a trajetória do INCRA dentro dela.

Apesar de acontecer em meio a muitos conflitos, sob a responsabilidade do INCRA, a Política de Assentamentos Rurais, tem permitido o acesso a terra a milhares de trabalhadores rurais, além é claro, do acesso às ações estruturantes, como infraestrutura básica, luz, água, estradas e de medidas de apoio a financiamentos à atividades produtivas e de fomento à agroindústria, à comercialização e atividades pluriativas e solidárias, que dão sustentabilidade a essas unidades, favorecendo a melhoria da capacidade de produção e renda dessas famílias (MONTE, 2013).

Monte (2013) destaca também, que a política de assentamentos passou a ser concebida como uma medida de preservação de populações tradicionais, como é o caso dos assentamentos de realocação de populações atingidas pela construção de hidroelétricas, assentamentos agroextrativistas de populações de seringueiros e ribeirinhos, as reservas extrativistas (Resex), principalmente na Amazônia.

Em razao dessa atuação heterogênea do Estado em vários territórios e regiões do País, existem também diversos tipos de assentamentos rurais onde o INCRA passou a atuar conforme Quadros 1 e 2 a seguir, onde se podem verificar os tipos e as formas de atuação do órgão neles, que os dividiu em dois grupos:

Grupo 1 - Projetos de Assentamento (PA's) de Reforma Agrária, criados por meio de obtenção de terras pelo INCRA, na forma tradicional, denominados (PAs); os ambientalmente diferenciados, denominados Projetos de Assentamento Agroextrativista (PAEs), Projeto de Desenvolvimento Sustentável (PDS), Projeto de Assentamento Florestal (PAF) e Projeto Descentralizado de Assentamento Sustentável (PDAS) (INCRA, 2018b).

Grupo 2 - Projetos de Assentamentos de Reforma Agrária reconhecidos pelo INCRA, criados por outras instituições governamentais 
para acesso às Políticas Públicas do Plano Nacional de Reforma Agrária (PNRA) (INCRA, 2018b).

Para uma melhor compreensão disso, é importante destacar que todos esses tipos de assentamentos, se enquadram num modelo de política de obtenção de terras, quais sejam: adjudicação, cessão, compra, confisco, desapropriação, doação, incorporação, reconhecimento e transferência.

Os tipos que possuem maior quantidade são o PA e o PE que têm origem nas ações dos movimentos sociais de trabalhadores rurais, em geral por meio das ocupações, sendo destinados na maior parte dos casos a agricultores que não possuem terra. O PA é implantado pelo Governo Federal e o PE pelos governos estaduais. Depois a implantação dos PE’s pelos governos estaduais, estes são reconhecidos pelo Governo Federal. Os demais, como pode ser verificado nos Quadros 01 e 02 a seguir, têm origem e funções como: das terras ocupadas por comunidades tradicionais (PFP, PAM, TRQ, PCA); promoção do desenvolvimento sustentável, com forte apelo ambiental (FLONA, PAE, PAF, PDS, RDS e RESEX), colonização (PAC, PDA, PIC e PC); compensação por passivos sociais (PRB) etc.

\section{Quadro 1 - Modalidades de Projeto criados pelo Incra atualmente}

\begin{tabular}{|c|c|c|}
\hline \multicolumn{3}{|r|}{ Grupo 1 - modalidades de projeto criados pelo incra atualmente } \\
\hline Modalidade & Sigla & Características \\
\hline $\begin{array}{l}\text { projeto de Assentamento } \\
\text { Federal }\end{array}$ & $\mathrm{PA}$ & $\begin{array}{l}\text { - Obtenção da terra, criação do Projeto e seleção dos beneficiários é de responsabilidade } \\
\text { da União por meio do Incra; } \\
\text { - Aporte de recursos de crédito Apoio à Instalação e de crédito de produção de } \\
\text { responsabilidade da União; } \\
\text { - Infraestrutura básica (estradas de acesso, água e energia elétrica) de responsabilidade da } \\
\text { União; } \\
\text { - Titulação (Concessão de Uso/Título de Propriedade) de responsabilidade da União. }\end{array}$ \\
\hline $\begin{array}{c}\text { Projeto de } \\
\text { Assentamento } \\
\text { Agroextrativista }\end{array}$ & PAE & $\begin{array}{l}\text { - Obtenção da terra, criação do Projeto e seleção dos beneficiários é de responsabilidade } \\
\text { da União por meio do Incra; } \\
\text { - Aporte de recursos de crédito Apoio a Instalação e de crédito de produção de } \\
\text { responsabilidade da união; } \\
\text { - Infraestrutura básica (estradas de acesso, água e energia elétrica) de responsabilidade da } \\
\text { União; } \\
\text { - Titulação (Concessão de Uso) de responsabilidade da União; } \\
\text { - Os beneficiários são geralmente oriundos de comunidades extrativistas; atividades } \\
\text { ambientalmente diferenciadas. }\end{array}$ \\
\hline $\begin{array}{c}\text { Projeto de } \\
\text { Desenvolvimento } \\
\text { Sustentável }\end{array}$ & PDS & $\begin{array}{l}\text { - Projetos de Assentamento estabelecidos para o desenvolvimento de atividades } \\
\text { ambientalmente diferenciadas e dirigido para populações tradicionais (ribeirinhos, } \\
\text { comunidades extrativistas,etc.); } \\
\text { - Obtenção da terra, criação do Projeto e seleção dos beneficiários é de responsabilidade } \\
\text { da União por meio do INCRA; } \\
\text { - Aporte de recursos de crédito Apoio a Instalação e de crédito de produção (Pronaf A e } \\
\text { C) de responsabilidade do Governo Federal; } \\
\text { - Infraestrutura básica (estradas de acesso, água e energia elétrica) de responsabilidade } \\
\text { da União; Não há a individualização de parcelas (Titulação coletiva - fração ideal) e a } \\
\text { titulação de responsabilidade da União. }\end{array}$ \\
\hline
\end{tabular}




\begin{tabular}{|c|c|c|}
\hline \multicolumn{3}{|r|}{ Grupo 1 - modalidades de projeto criados pelo incra atualmente } \\
\hline Modalidade & Sigla & \begin{tabular}{|c|c|} 
& Características \\
\end{tabular} \\
\hline $\begin{array}{l}\text { projeto de Assentamento } \\
\text { Florestal }\end{array}$ & PAF & $\begin{array}{l}\text { - É uma modalidade de assentamento, voltada para o manejo de recursos florestais em áreas } \\
\text { com aptidão para a produção florestal familiar comunitária e sustentável, especialmente } \\
\text { aplicável à Região Norte; a produção florestal madeireira e não madeireira no PAF deverá } \\
\text { seguir as regulamentações do Ibama para Manejo Florestal Sustentável, considerando as } \\
\text { condições de incremento de cada sítio florestal; Tais áreas serão administradas pelos } \\
\text { produtores florestais assentados, por meio de sua forma organizativa, associação ou } \\
\text { cooperativas, que receberá o Termo de Concessão de Uso; } \\
\text { - O INCRA, em conjunto com Ibama, órgãos estaduais e a sociedade civil organizada, } \\
\text { indicarão áreas próprias para implantação dos PAF's. }\end{array}$ \\
\hline $\begin{array}{c}\text { Projeto de } \\
\text { Assentamento Casulo } \\
\text { (Modalidade revogada } \\
\text { pela Portaria INCRA } \\
\text { no 414, de } 11 \text { de julho } \\
\text { de 2017, publicada no } \\
\text { Diário Oficial da União } \\
\text { de } 12 \text { de julho de 2017) }\end{array}$ & PCA & $\begin{array}{l}\text { - Projeto de Assentamento criado pelo município ou pela União; } \\
\text { - A União pode participar com os recursos para a obtenção de recursos fundiários, mas a } \\
\text { terra pode ser do município ou da União; } \\
\text { - Aporte de recursos de Crédito Apoio a Instalação e de crédito de produção (Pronaf A e } \\
\text { C) de responsabilidade do Governo Federal; } \\
\text { - Infraestrutura básica (estradas de acesso, água e energia elétrica) de responsabilidade do } \\
\text { Governo Federal e Municipal; } \\
\text { - Diferencia-se pela proximidade a centros urbanos e pelas atividades agrícolas geralmente } \\
\text { intensivas e tecnificadas; } \\
\text { - Titulação de responsabilidade do município. }\end{array}$ \\
\hline $\begin{array}{c}\text { Projeto Descentralizado } \\
\text { de Assentamento } \\
\text { Sustentável }\end{array}$ & PDAS & $\begin{array}{l}\text { - Modalidade descentralizada de assentamento destinada ao desenvolvimento da } \\
\text { agricultura familiar pelos trabalhadores rurais sem-terra no entorno dos centros urbanos, } \\
\text { por meio de atividades economicamente viáveis, socialmente justas, de caráter inclusivo } \\
\text { e ecologicamente sustentáveis; } \\
\text { - As áreas serão adquiridas pelo INCRA por meio de compra e venda ou ainda doadas ou } \\
\text { cedidas pelos governos estaduais e municipais; } \\
\text { - Os lotes distribuídos não podem ter área superior a dois módulos fiscais ou inferior à } \\
\text { fração mínima de parcelamento em cada município; } \\
\text { - O desenvolvimento das atividades agrícolas deve garantir a produção de } \\
\text { hortifrutigranjeiros para os centros urbanos; } \\
\text { - O Incra e o órgão estadual ou municipal de política agrária, ou equivalente, deverão firmar } \\
\text { Acordo de Cooperação Técnica visando garantir as condições mínimas necessárias para } \\
\text { que as famílias assentadas tenham acesso às políticas públicas para o desenvolvimento do } \\
\text { futuro projeto de assentamento. }\end{array}$ \\
\hline \multicolumn{3}{|c|}{$\begin{array}{l}\text { Observação: Além das modalidades descritas, o INCRA já criou e tem cadastrado em seu Sistema de Informações de Projetos } \\
\text { da Reforma Agrária (SIPRA) os Projetos de Colonização (PC), os Projetos Integrados de Colonização (PIC), os Projetos de } \\
\text { Assentamento Rápido (PAR), Projetos de Assentamento Dirigido (PAD), Projetos de Assentamento Conjunto (PAC) e Projetos } \\
\text { de Assentamento Quilombola (PAQ). Todas essas modalidades deixaram de ser criadas a partir da década de 1990, quando } \\
\text { entraram em desuso. }\end{array}$} \\
\hline
\end{tabular}

Fonte: INCRA (2018b). 
Quadro 2 - Modalidades de áreas reconhecidas pelo INCRA

\begin{tabular}{|c|c|c|}
\hline \multicolumn{3}{|c|}{ Grupo 2 - modalidades de áreas reconhecidas pelo incra } \\
\hline Modalidade & Sigla & \begin{tabular}{|l|} 
Características \\
\end{tabular} \\
\hline $\begin{array}{l}\text { projeto de Assentamento } \\
\text { Estadual }\end{array}$ & $\mathrm{PE}$ & $\begin{array}{l}\text { - Obtenção da terra,criação do Projeto e seleção dos beneficiários éde Responsabilidade } \\
\text { das Unidades Federativas; } \\
\text { - Aporte de recursos de crédito e infraestrutura de responsabilidade das Unidades } \\
\text { Federativas segundo seus programas fundiários; } \\
\text { - Há a possibilidade de participação da União no aporte de recursos relativos à } \\
\text { obtenção de terras, Crédito Apoio à Instalação e produção (Pronaf A e C) mediante } \\
\text { convênio; } \\
\text { - Há a possibilidade de participação da União no aporte de recursos relativos a } \\
\text { infraestrutura básica; } \\
\text { - O INCRA reconhece os Projetos Estaduais como Projetos de Reforma Agrária } \\
\text { viabilizando o acesso dos beneficiários aos direitos básicos estabelecidos para o } \\
\text { Programa de Reforma Agrária; } \\
\text { - Titulação de responsabilidade das Unidades Federativas. }\end{array}$ \\
\hline $\begin{array}{l}\text { Projeto de Assentamento } \\
\text { Municipal }\end{array}$ & PAM & $\begin{array}{l}\text { - Obtenção da terra,criação do Projeto e seleção dos beneficiáriosé de responsabilidade } \\
\text { dos municípios; } \\
\text { - Aporte de recursos de crédito e infraestrutura de responsabilidade dos municípios; } \\
\text { - Há a possibilidade de participação da União no aporte de recursos relativos à } \\
\text { obtenção de terras, Crédito Apoio à Instalação e produção (Pronaf A e C) mediante } \\
\text { convênio; } \\
\text { - Há a possibilidade de participação da União no aporte de recursos relativos a } \\
\text { infraestrutura básica; } \\
\text { - O INCRA reconhece os Projetos Municipais como de Reforma Agrária viabilizando } \\
\text { o acesso dos beneficiários aos direitos básicos estabelecidos para o Programa de } \\
\text { Reforma Agrária; } \\
\text { - Titulação de responsabilidade dos municípios. }\end{array}$ \\
\hline Reservas Extrativistas & RESEX & $\begin{array}{l}\text { - Reconhecimento pelo INCRA de áreas de Reservas Extrativistas (RESEX) como } \\
\text { Projetos de Assentamento viabilizando o acesso das comunidades que ali vivem aos } \\
\text { direitos básicos estabelecidos para o Programa de Reforma Agrária; } \\
\text { - A obtenção de terras não é feita pelo INCRA, mas pelos órgãos ambientais federais } \\
\text { ou estadual quando da criação das RESEX. }\end{array}$ \\
\hline $\begin{array}{l}\text { Território Remanescentes } \\
\text { Quilombola }\end{array}$ & TRQ & $\begin{array}{l}\text { - Decretação da área pela União visando à regularização e ao estabelecimento de } \\
\text { comunidades remanescentes de quilombos; } \\
\text { - Aporte de recursos para a obtenção de terras, crédito e infraestrutura realizado pela } \\
\text { União por meio de açôes integradas com a Fundação Palmares e outras instituições. }\end{array}$ \\
\hline $\begin{array}{l}\text { Reconhecimento de } \\
\text { Assentamento de Fundo } \\
\text { de Pasto }\end{array}$ & PFP & $\begin{array}{l}\text { - Projetos criados pelo estado ou municípios; } \\
\text { - Esses projetos são reconhecidos o pelo INCRA como beneficiárias do Programa } \\
\text { Nacional de Reforma Agrária (PNRA), viabilizando o acesso das comunidades que } \\
\text { ali vivem ao Pronaf A. }\end{array}$ \\
\hline $\begin{array}{l}\text { Reassentamento de } \\
\text { Barragem }\end{array}$ & PRB & $\begin{array}{l}\text { - A implantação é de competência dos empreendedores e o INCRA reconhece como } \\
\text { beneficiário do PNRA, quando eles passam a ter direito ao Pronaf A, Assistência } \\
\text { Técnica Social e Ambiental (ATES) e Pronera. }\end{array}$ \\
\hline Floresta Nacional & FLONA & $\begin{array}{l}\text { - A obtenção de terras não é feita pelo INCRA, mas pelos órgãos ambientais federais } \\
\text { quando da criação das FLONAS. }\end{array}$ \\
\hline $\begin{array}{l}\text { Reserva de } \\
\text { Desenvolvimento } \\
\text { Sustentável }\end{array}$ & RDS & $\begin{array}{l}\text { - De competência do Ibama; } \\
\text { - São unidades de conservação de uso sustentável reconhecidas pelo INCRA como } \\
\text { beneficiárias do Programa Nacional de Reforma Agrária (PNRA), viabilizando } \\
\text { o acesso das comunidades que ali vivem aos direitos básicos como créditos de } \\
\text { implantação e produção (Pronaf A); O reconhecimento de RDS como beneficiária } \\
\text { do PNRA, feito por analogia, à portaria de reconhecimento das RESEX. }\end{array}$ \\
\hline
\end{tabular}

Fonte: INCRA (2018b). 
Os autores, Girardi e Fernandes (2008, p.84), analisaram o que eles chamam de "[...] potencialidade reformadora dos diversos tipos de assentamentos rurais", em seu estudo levam em conta a origem da terra para a criação dos assentamentos para caracterizá-los como reformadores e não reformadores.

O grupo dos assentamentos reformadores abrange os tipos PA,PAM, PCA e PE, cujas terras de origem são, em grande parte, desapropriadas, ou seja, o governo federal paga por elas. $\mathrm{O}$ grupo de não reformadores compreende o grupo cujas características são: PFP, PAM, PCA, TRQ: reconhecimento de terras e beneficiários ${ }^{1}$; FLONA, PAE, PAF, PDS, RDS, RESEX: caráter ambiental, reconhecimento de terras e beneficiários; PAC, PC e PIC: projetos de colonização de novas áreas; PDA: colonização e titulação; PAR: titulação de posses; PRB: beneficiários e compensação de passivo social (GIRARDI, FERNANDES, 2008).

No caso dos assentamentos não reformadores o campesinato se territorializa sem que haja a desterritorialização do latifúndio. Para os assentamentos reformadores as terras são arrecadadas geralmente a partir de desapropriação, o que representa o mais alto grau de reforma da estrutura fundiária possível na legislação brasileira atual. Através da criação desses tipos de assentamentos é cumprido o artigo 186 da Constituição e a estrutura fundiária é de fato desconcentrada: com os assentamentos reformadores o campesinato se territorializa a partir da desterritorialização do latifúndio e isso é reforma da estrutura fundiária (GIRARDI, FERNANDES, 2008, p. 86).

Um exemplo prático são os PAE's, que estão localizados todos na Amazônia, mais especificamente no estado do Pará e do Amazonas, que foram criados para atender as populações tradicionais ribeirinhas, principalmente no arquipélago do Marajó.

Os autores concluíram que os governos não alteraram a estrutura fundiária em regiões de ocupação consolidada como a Amazônia, pois utilizaram mais, o modelo de assentamento não reformador, como os PAE's, RESEX, PDS, etc, que em estados como o Pará e o Amazonas, são mais de $50 \%$ do total de projetos criados em todas as modalidades, e nas outras regiões do País, a alegação para não reforma agrária, é o preço das terras.

É certo que a Reforma Agrária avançou nas últimas décadas, não tanto como esperavam os movimentos sociais de agricultores, mas houve, sim, uma multiplicidade de intervenções governamentais nas ações fundiárias, por meio do INCRA, que segundo Monte (2013, p. 66),

Consubstancia uma nova relação do homem do campo e sua família com a posse e uso dos recursos naturais, que se traduz na melhoria da organização socioeconômica da população assentada e das condições ambientais e de sustentabilidade dos assentamentos, concorrendo, por extensão, para uma nova feição agrária.
1 Por beneficiários, designamos as formas de assentamentos em que o acesso a terra não foi possibilitado pelo Estado, que atuou principalmente com o reconhecimento do direito de uso ou de propriedade. Os beneficiários são contabilizados como assentados pelo fato de terem direito a recursos financeiros de estabelecimento na terra e créditos direcionados à agricultura familiar. 
Ou seja, a criação dos Projetos de Assentamento sob a responsabilidade do INCRA, tem, numa visão política, o reconhecimento das lutas e conflitos legítimos daquelas populações por muito tempo e por vezes esquecidas, dando a elas o acesso a terra e aos seus direitos que lhes são conferidos na Constituição Federal de 1988.

Como produto dessa ação política, os assentamentos estão submetidos aos efeitos da gestão institucional do INCRA, que é o órgão responsável em prover os mesmos com a estrutura necessária à sua viabilização, e que, portanto, uma vez implantados, requerem do órgão, todos os esforços tanto administrativos como técnicos que promovam o seu desenvolvimento, a sua consolidação, com eficácia, eficiência e efetividade.

\section{Procedimentos Metodológicos}

\section{Caracterização da pesquisa}

Este trabalho tem por característica ser um estudo de caso. Construído por meio de técnicas de coleta de dados, o que, para Yin (2005, p. 82), "pode ser uma atividade complexa e difícil. Se não for realizada corretamente, todo o trabalho de investigação do estudo de caso poderá ser posto em risco $[\ldots]$ ”.

É de caráter documental e, quanto a isto Marconi e Lakatos (2010, p. 157) dizem que, “[...] está restrita a documentos, escritos ou não, constituindo o que se denomina de fontes primárias”, realizada tanto no início quanto depois da ocorrência. Ainda, foi efetuada pesquisa exploratória descritiva que para Marconi e Lakatos (2010, p. 171) tem “[...] por objetivo descrever completamente determinado fenômeno, como, por exemplo, o estudo de um caso para o qual são realizadas análises empíricas e teóricas [...]”.

Do ponto de vista da abordagem, o trabalho apresenta características de pesquisa qualitativa, pois trata do caráter subjetivo dos documentos analisados, e também, é de caráter quantitativo, considerando a análise dos indicadores de obtenção de imóveis, famílias assentadas, supervisão ocupacional, dentre outros, bem como, do ponto de vista dos métodos é uma pesquisa bibliográfica, pois constroem seus argumentos a partir de material já publicado, qual sejam, teorias discutidas na disciplina de Políticas Públicas e Sustentabilidade, e de pesquisa documental, elaborada a partir de materiais que não receberam tratamento analítico, elaborados pelo INCRA e manejados pelos autores.

\section{Delineamento}

Metodologicamente, o estudo é realizado com base em pesquisa documental, nos dados e informações referentes aos resultados numéricos da 
Política de Reforma Agrária, por meio dos indicadores de Imóveis Obtidos, PA's criados, Famílias Assentadas e os resultados do monitoramento desses projetos, por meio do indicador de Supervisão Ocupacional, disponibilizados pelo INCRA nos Relatórios de Gestão, Manuais de Indicadores, estudos específicos da Diretoria de Gestão Estratégica, disponíveis tanto no site oficial do órgão, como no sistema wiki.incra.gov. br, de uso restrito da instituição, onde estão depositados todos os relatórios, estudos como "Execução Física de 1995 a 2016" elaborado pela Divisão de Monitoramento da Gestão (DEA-1), e o detalhamento das ações executadas pelo INCRA.

Este estudo faz um resgate latente das teorias sobre Políticas Públicas desenvolvidas na disciplina de Políticas Públicas e Sustentabilidade, e um breve histórico da Política de Assentamentos Rurais, apresentando ainda os principais indicadores da política de assentamento de famílias, demonstrando os resultados quantitativos dessa política, sem a pretensão de avaliar impactos dessa política em qualquer meio, mas de levantar hipóteses para uma futura pesquisa aplicada.

\section{Resultados e Discussões}

Os indicadores da Política de Reforma Agrária, foram construídos a partir da definição das ações dentro do Programa 2066 - Reforma Agrária e Governança Fundiária, estabelecido nos Planos Plurianuais - PPA's, vigente 2016-2019, consignado na Lei Orçamentária Anual e acompanhado pelo documento chamado Caderno de Metas elaborado pelo INCRA anualmente (INCRA, 2018c).

Indicador de Imóveis Obtidos por meio de Decretos Presidenciais:

É dado pelo número de decretos presidenciais publicados no Diário Oficial da União anualmente. Já apresentado na fundamentação teórica conforme Gráfico 1.

Indicador de Projetos de Assentamentos Criados:

É dado pelo número de Projetos de Assentamentos criados anualmente. Tais assentamentos podem ser divididos em dois grupos, conforme as modalidades apresentadas nos Quadros 1 e 2 a seguir: 
Quadro 3 - GRUPO I - Modalidades de projetos criados pelo INCRA atualmente

\begin{tabular}{|l|c|}
\hline Modalidade & Sigla \\
\hline projeto de Assentamento Federal & PA \\
\hline Projeto de Assentamento Agroextrativista & PAE \\
\hline Projeto de Desenvolvimento Sustentável & PDS \\
\hline Projeto de Assentamento Florestal & PAF \\
\hline $\begin{array}{l}\text { Projeto de Assentamento Casulo - (Modalidade revogada pela Portaria Incra no 414, de 11 de julho } \\
\text { de 2017, publicada no Diário Oficial da União de 12 de julho de 2017). }\end{array}$ & PCA \\
\hline Projeto Descentralizado de Assentamento Sustentável & PDAS \\
\hline $\begin{array}{l}\text { Observação: Além das modalidades acima, o Incra já criou e tem cadastrado em seu Sistema de Informações de } \\
\text { PA's (SIPRA) os Projetos de Colonização (PC), os Projetos Integrados de Colonização (PIC), os Projetos de }\end{array}$ \\
$\begin{array}{l}\text { Assentamento Rápido (PAR), Projetos de Colonização Particular (PAP), Projetos de Assentamento Dirigido (PAD) } \\
\text { e Projetos de Assentamento Conjunto (PAC). Todas essas modalidades deixaram de ser criadas a partir da década } \\
\text { de 1990, quando entraram em desuso. }\end{array}$ \\
\hline
\end{tabular}

Fonte: INCRA (2018b).

Quadro 4 - Grupo 2 - Modalidades de áreas reconhecidas pelo INCRA

\begin{tabular}{|l|c|}
\hline Modalidade & Sigla \\
\hline projeto de Assentamento Estadual & PE \\
\hline Projeto de Assentamento Municipal & PAM \\
\hline Programa Nacional de Crédito Fundiário (antigo Programa Cédula da Terra) & PCT \\
\hline Reservas Extrativistas & RESEX \\
\hline Território Remanescentes Quilombola & TRQ \\
\hline Reconhecimento de Assentamento de Fundo de Pasto & PFP \\
\hline Reassentamento de Barragem & PRB \\
\hline Floresta Nacional & FLONA \\
\hline Reserva de Desenvolvimento Sustentável & RDS \\
\hline
\end{tabular}

Fonte: INCRA (2018b)

No Gráfico 2 a seguir,são apresentados os dados dos esforços empregados pelo INCRA, na criação e reconhecimento de PA's, em todo o Brasil.

Gráfico 2 - Projetos de assentamentos criados até 2017 - BRASIL

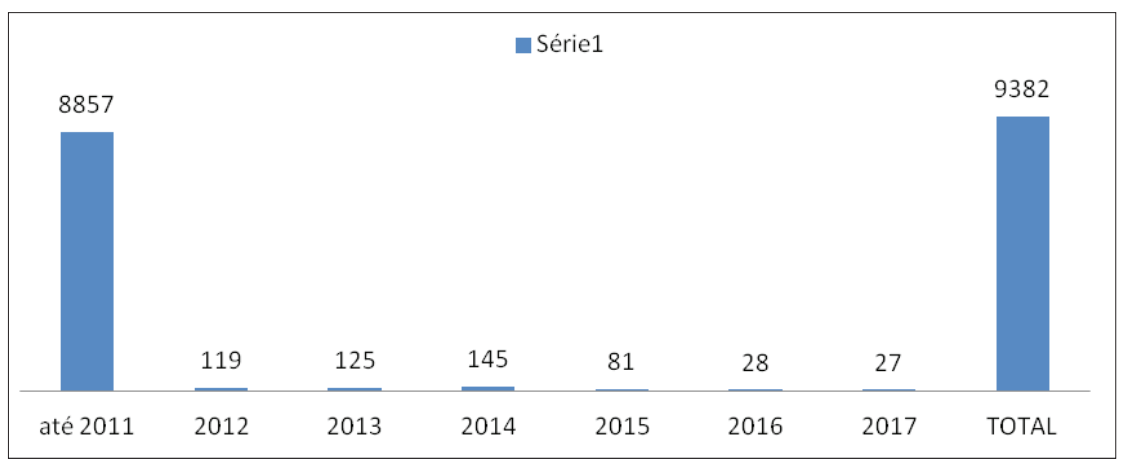

Fonte: INCRA (2018c) 
Percebe-se, ainda, como no gráfico apresentado no indicador de imóveis obtidos por decreto presidencial, que a criação de PA's, vem numa queda acentuada nos últimos seis anos. Pode ocorrer ainda, segundo dados do INCRA, que um projeto criado num ano, tenha sido concebido por meio a um decreto de anos anteriores. Não corresponde ao mesmo número de imóveis obtidos, pois estão divididos conforme às modalidades apresentadas nos Quadros 1 e 2, ou seja, por obtenção onerosa ou não ou por reconhecimento.

\section{Indicador de Famílias Assentadas:}

Obtido ou reconhecido o imóvel, cria-se o projeto, cadastramse as famílias que serão selecionadas e homologadas a partir de critérios específicos. O indicador é dado pelo número de famílias assentadas nos PA's, homologadas no Sistema de Informação de Projetos de Reforma Agrária - SIPRA e o resultado é apresentado no Gráfico 3 a seguir:

\section{Gráfico 3 - Famílias assentadas até 2017 - BRASIL}

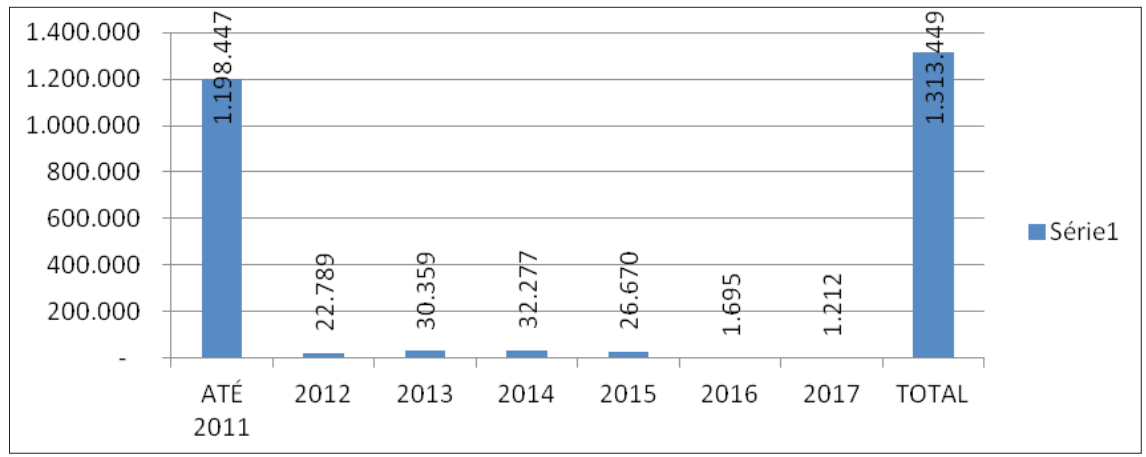

Fonte: INCRA (2018c).

O INCRA disponibiliza no site oficial: www.incra.gov.br, um link chamado de "Painel de Assentamentos", onde qualquer cidadão tem acesso as informações gerais sobre os assentamentos da Reforma Agrária.

O número de famílias assentadas que permanecem nos lotes, segundo a planilha gerada no Painel de Assentamentos, é de 972.289 mil, famílias assentadas e 9.374 mil, Projetos de Assentamento criados, com uma capacidade para assentar 1.179.058 milhão, famílias até 31/12/2017. Essa diferença está no fato do órgão não diferenciar, família assentada em assentamentos novos criados, com aquelas famílias que são oriundas da regularização de lotes que foram vendidos, abandonados, permutados etc., fruto da supervisão ocupacional, e que atendem aos normativos que regulamentam os Projetos de Assentamento.

A diferença entre o número de famílias assentadas e a capacidade de assentamentos dos projetos, de acordo com o INCRA, é, ou de lotes vagos, 
ou problemas oriundos de alterações no número de parcelas dos projetos que não sofreram alteração no SIPRA. Sobre o SIPRA, são inúmeros os problemas apontados pelos técnicos e pelos Órgãos de Controle.

Não é pretensão deste estudo aprofundar tais problemas, mas gerar hipóteses para uma futura pesquisa aplicada, quais sejam: as informações sobre as famílias assentadas e projetos criados pelo INCRA, correspondem às famílias que estão nos lotes? Que tratamento o INCRA vem dando para solucionar os problemas em seu principal sistema de monitoramento dos referidos projetos?

Indicador de Supervisão Ocupacional:

De acordo com o Manual de Indicadores, este indicador é executado por meio da Ação 211A - PO AO - Supervisão Ocupacional de Projetos de Assentamento, que de acordo com a descrição:

Trata-se de atividade essencial ao processo de desenvolvimento das áreas de reforma agrária. [...] em caso de flagrante de ocupação irregular, de ofício, o INCRA, toma as medidas administrativas com vistas à sua regularização ou retomada das parcelas, além da consequente redestinação da área. Ações possessórias são ajuizadas pela Procuradoria Especializada, em caso de descumprimento das decisões administrativas para ocupação regular da área (INCRA, 2015, p. 2).

Ou seja, o indicador reflete o número de lotes/parcelas supervisionadas com o "laudo entregue", ou seja, independentemente da situação encontrada nos trabalhos de campo realizados pelo INCRA, regular ou irregular, conforme apresentado no Gráfico 4 a seguir:

Gráfico 4 - Supervisão Ocupacional - Laudo Entregue - 2010-2017

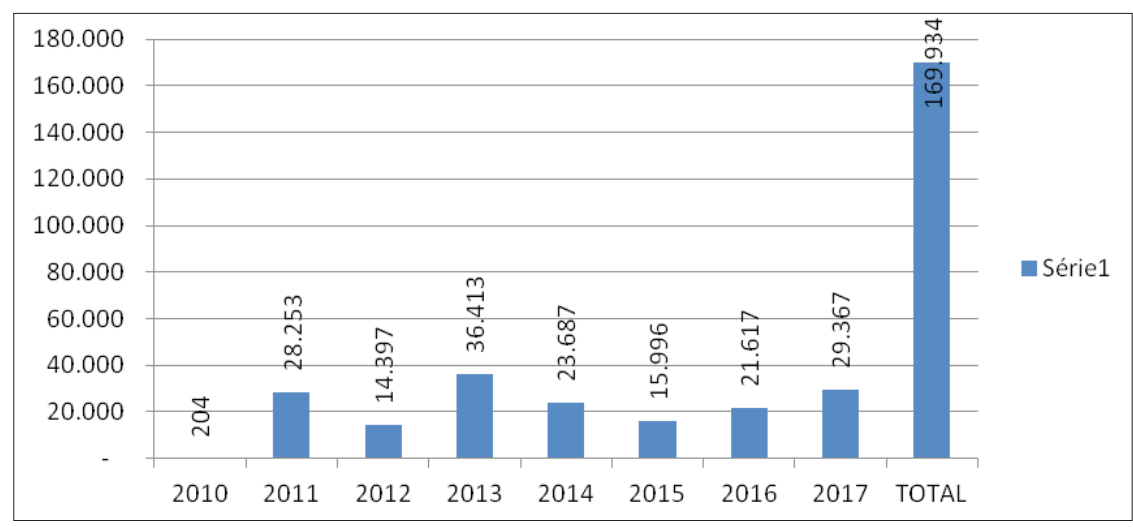

Fonte: INCRA (2018c). 
Conforme as informações do Relatório Execução Física 1995 a 2016, os dados de Supervisão Ocupacional começaram a ser monitorados em 2010. Não se obteve a informação se esse trabalho era realizado anteriormente. Como descrito no Manual de Indicadores, essa é uma atividade essencial para o monitoramento dos Projetos de Assentamento. É com ela que o órgão pode verificar se as leis e os normativos que regulamentam os Projetos de Assentamento estão sendo cumpridos pelas famílias, além de obter todas as demais informações para planejamento das sobre as ações de responsabilidade do INCRA, quanto ao desenvolvimento dos referidos projetos.

Quando se analisa os dados da Supervisão, pode-se concluir que em relação ao número de famílias assentadas, o resultado é muito aquém da necessidade. Em oito anos, em torno de 18\% das parcelas foram supervisionadas com laudos entregues pelos técnicos. O que demonstra uma total ausência do órgão nos Projetos de Assentamentos.

Destaque-se que as informações constantes nos Relatórios de Gestão da Autarquia de 2014, dão conta de que essa ação foi suspensa “[...] em função da edição da MP 636/2013 que resultou na publicação da Lei n. 13.001/2014 e, posteriormente, foi limitada para atender decisão da justiça com prazo e penalidades para o gestor, resolução de conflitos graves e ações de retomadas de lotes ou parcelas, conforme orientação constante do Mem. 158/2014-DD” (INCRA, 2014, p.59). Só em 2016, com a edição do Acórdão 775/2016 que paralisou algumas ações do INCRA, é que foram liberados os trabalhos de forma geral, os quais vinham sendo executados em algumas Superintendências Regionais, ou por pendências, ou por força de ações judiciais.

$\mathrm{O}$ que fundamentou esse Acórdão do TCU foram as inúmeras irregularidades que vinham sendo apontadas pelo órgão em outros acórdãos, dois em 2004 e outro de 2008. Desde a ausência de ampla divulgação do processo de seleção das famílias, às inconsistências na base de dados do SIPRA. Em ambos, a recomendação era para que o INCRA estabelecesse a obrigatoriedade de supervisão periódica da utilização dos lotes, a fim de cumprir a legislação agrária, além de recomendar o cumprimento da legislação para a seleção e homologação de famílias, bem como as melhorias no SIPRA, que apresentava várias fragilidades (BRASIL, 2016-0 p. 15).

Uma leitura rápida do acórdão já desperta para uma série de hipóteses quanto à execução da Política de Reforma Agrária estar atingindo os seus objetivos estabelecidos lá na sua implementação.

\section{Conclusões}

Do resgate teórico sobre o processo de uma Política Pública o ponto importante deste trabalho é o da avaliação. Mas vale destacar primeiro que a Política de Reforma Agrária seguiu as fases conforme destacado por Dye 
(2011) e Silva (2012): de identificação do problema, que a história nos mostra que ocorre a partir da luta e do movimento das ligas camponesas que forçaram o governo militar a colocar na agenda política as suas reivindicações.

Ocorre, então, a formulação e a legitimação dessa política, com a edição do Estatuto da Terra, em 1964, dando início a sua fase de implementação em meados de 1970, porém, com medidas efetivas e de maior impacto, a partir do governo do presidente Fernando Henrique Cardoso.

Somente os relatórios de gestão, elaborados ano a ano, não conseguem dar conta de demonstrar se os objetivos dessa política estão sendo atingidos com eficiência, eficácia e efetividade, mesmo sabendo que centenas de famílias foram beneficiadas com o acesso à terra, não é possível verificar se os investimentos públicos realizados estão retornando tanto em forma de produção quanto de renda, porque o INCRA não dispõe de estudos específicos que demonstrem isso à sociedade.

Porém, não foi esse o objetivo deste trabalho, de aprofundar a pesquisa, além de apresentar os resultados numéricos por meio de indicadores do número de Imóveis Obtidos, Projetos de Assentamentos Criados, número de Famílias Assentadas, e o indicador de monitoramento desses projetos, o de Supervisão Ocupacional, com vistas a levantar hipóteses para futuras pesquisas acadêmicas, como: A Reforma Agrária atingiu os objetivos propostos estabelecidos na legislação que regulamenta e legitima esta política? O que está comprometido com os sucessivos acórdãos publicados pelo TCU? O INCRA tem como atender as recomendações apontadas pelo TCU?

Por isso, a importância do uso da avaliação de uma Política Pública, não como fase final do processo, mas na sua constância, permitindo corrigir distorções, "[...] deduzir consequências para ações e programas futuros" (FREY, 2000, p. 228), e, ainda de acordo com Silva (2012, p.31), "avaliação de políticas e programas governamentais permitem que formuladores e implementadores sejam capazes de tomar decisões com maior qualidade, maximizando o gasto público nas diversas atividades objeto de intervenção estatal [...]”. Por conseguinte, é de grande importância que o INCRA organize seus sistemas, capacite seus técnicos, e atente para a avaliação dos seus resultados concretamente.

Levando em consideração o que diz Januzzi (2002), os indicadores apresentados, dispõem de cobertura populacional adequada aos propósitos da política, são específicos do programa de Reforma Agrária, diretamente relacionados com a criação de Projetos de Assentamento e de famílias assentadas, e mesmo com a fragilidade dos Sistemas do INCRA, apresentam certa confiabilidade nos dados, e gozam de historicidade, pois foi possível acessar dados desde a implementação da referida política, e assim cumprir 
com o principal objetivo do trabalho que foi o de apresentar os números da Reforma Agrária por meio dos seus principais indicadores, sendo que pode ser verificado que a cada mudança de governo, a agenda política da Reforma Agrária sofreu alterações significativas.

O presente estudo apresenta possibilidades de futuras pesquisas, pois não deu conta de analisar a complexidade do programa de Reforma Agrária como um todo, tendo como principal limitação o tempo da pesquisa, e a dispersão dos dados disponibilizados pelo INCRA.

\section{Referências}

INSTITUTO NACIONAL DE COLONIZAÇÃO E REFORMA AGRÁRIA - INCRA. Manual de Indicadores do Módulo de Monitoramento. INCRA, Brasília, 09 de nov, 2015.

BRASIL. INSTITUTO NACIONAL DE COLONIZAÇÃO E REFORMA AGRÁRIA - INCRA. Criação e Modalidades de Assentamentos. 2018a. Disponível em: <http://www.incra.gov.br/assentamentosmodalidades\#grupo2>. Acesso em 10 maio 2018.

INSTITUTO NACIONAL DE COLONIZAÇÃO E REFORMA AGRÁRIA - INCRA. Execução Fisica_historico 1995 a 2016; Relatórios de Gestão 2011-17. Disponível em:wiki.incra.gov.br. Acesso em 15 maio 2018b.

. INSTITUTO NACIONAL DE COLONIZAÇÃO E REFORMA AGRÁRIA - INCRA. Reforma Agrária. Disponível em:<http://www.incra.gov. br/reforma_agraria> 2018c. Acesso em 10 de maio de 2018.

BRASIL. Lei n. 4.504, de 30 de novembro de 1964. Dispõe sobre o Estatuto da Terra, e dá outras providências, Brasília, DF, 2017. Disponível em: <http://www. planalto.gov.br/ccivil_03/Leis/L4504.htm>. Acesso em: 16 maio 2018.

BRASIL. Tribunal de Contas da União. TC 000.517/2016-0 - Acórdão n ${ }^{\circ}$ 775/2016 - TCU - Plenário. Unidade Técnica: Secretaria de Controle Externo da Agricultura e do Meio Ambiente (SecexAmb). Brasília, 2016. Disponível em: https://portal.tcu.gov.br/lumis/portal/file/fileDownload.jsp?fileId=8A8182A253 D4239E0153F24D7BAC2406\&inline=1. Acesso em: 16 outubro 2018.

DYE, Thomas T. R.Understanding public policy. 13 ed.USA: Pearson Education, 2011.

FABRINI, J. E. A cooperação agrícola nos assentamentos: uma proposta política. Geografia, Londrina, v. 9, n. 1, p. 67-78, jan/jun. 2000. Disponível em: <http://www.uel.br/revistas/uel/index.php/geografia/article/view/10177>.Acesso em16/12/2018.

FOCA BRASIL. Artigos da Reforma Agrária. Guedes \& Guedes, qual será o seu legado? 2018. Disponível em:<http://www.focabrasil.com.br/arefagraria. html\#acrise>. Acesso em 15 maio 2018.

FREY, Klaus. Políticas Públicas: um debate conceitual e reflexões referentes à prática da análise de políticas públicas no Brasil. Planejamento e Políticas Públicas, Brasília, n. 21, jun. 2000. 
GELINSKI, Carmem R. O. G. SEIBEL, Erni J.Formulação de políticas públicas: questões metodológicas relevantes. Revista de Ciências Humanas, Florianópolis, v. 42, n. I e 2, p. 227-240, abr./out 2008.

GIRARDI, E. P.; FERNANDES, B. M. A luta pela terra e a política de assentamentos rurais no Brasil. A reforma agraria conservadora. Agrária, São Paulo, n. 8, p.73-98, 2008. Disponível em: <http://www.revistas.usp.br/agraria/ article/view/157/157>. Acesso em 20 nov. 2018.

JANUZZI, Paulo M. Considerações sobre o uso, mau uso e abuso dos indicadores sociais na formulação e avaliação de Políticas Públicas municipais. Revista de Administração Pública. Rio de Janeiro v.36 n.(1, p.51-72, jan./fev. 2002.

KRAFT, Michael E.; FURLONG, Scott R. Public Policy: politics, analysis and alternatives. 3 ed. USA: CQPress, 2010.

MARCONI, M. A.; LAKATOS, E. M. Fundamentos de metodologia científica. 7. ed. São Paulo: Atlas, 2010.

MONTE, .F. C. D. O INCRA e a Política de Assentamentos Rurais: um estudo sobre processos político-administrativos de ação pública. 2013. Tese (Doutorado em Ciências Sociais em Desenvolvimento) - Programa de Pós-Graduação em Ciências Sociais em Desenvolvimento. Agricultura e Sociedade. Universidade Federal Rural do Rio De Janeiro, 2013. Disponível em: < https://sucupira.capes.gov. $\mathrm{br} /$ sucupira/public/consultas/coleta/trabalhoConclusao/viewTrabalhoConclusao. jsf?popup=true\&id_trabalho=135616>. Acesso em 10 nov. 2018.

MOREIRA, Elaine Martins. O Assentamento Ireno Alves dos Santos em Rio Bonito do Iguaçu-PR: Desenvolvimento Socioeconômico e os Impactos da Política de Assentamentos para a Reforma Agrária. Emancipação, Ponta Grossa, 13, no Especial: 145-158, 2013. Disponível em: <http://www.revistas2.uepg.br/ index.php/emancipacao>. Acesso em 14 dez. 2018.

MOURA, I. F. Assentamentos Rurais: Agregação de valor e comercialização. O caso do Assentamento Santa Maria (Paranacity - PR). 2006. Dissertação (Mestrado em Economia) - Programa de Pós-Graduação em Desenvolvimento Econômico. Universidade Estadual de Campinas Instituto de Economia. Campinas, São Paulo, 2006. Disponível em <http://repositorio.unicamp.br/ handle/REPOSIP/286148>. Acesso em 20 dez. 2018.

SILVA, C.L. Políticas Públicas e desenvolvimento local: instrumentos e proposições de análise para o Brasil. Petrópolis: Vozes, 2012.

SOUZA, Celina. Políticas Públicas: uma revisão da literatura. Sociologias. Porto Alegre, Ano 8 n. 16, p. 20-45, jun./dez. 2006..

TREVISAN, Andrei P. BELLEN, Hans M. Avaliação de Políticas Públicas: uma revisão teórica de um campo em construção. Revista de Administração Pública, Rio de Janeiro v. 42 n. (3, p. 529-50), maio/jun. 2008.

TSUKAMOTO, Ruth Youko. ASARI, Alice Yatiyo. Assentamentos rurais e agricultura familiar: processo de territorialização e perspectivas de autosustentação. Geografia, Londrina, v. 12, n. 1, p. 483-494, - jan/jun. 2003. 
Disponível em: <http://www.ul.br/revistas/uel/index.php/geografia/article/ download/6708/6052>. Acesso em 19 dez. 2018.

YIN, R. K. Estudo de caso: planejamento e métodos. 3. ed.Porto Alegre: Bookman, 2005.

Submetido em: 08/07/2019

Aceito em: 05/08/2019 


\title{
PUBLIC POLICY AND AGRARIAN REFORM: AN ANALYSIS OFTHE MAIN INDICATORS OF RURAL SETTLEMENT POLICY
}

\begin{abstract}
The present article presents results of the main indicators of the Agrarian Reform Policy, from its implementation in the decade of 1970 until 2017. The methodology adopted was the case study, with the survey of data of the Rural properties obtained for creation purposes of Settlement Projects, Settlement Families and Occupational Supervision of these projects. The results show that with each change of government, the political agenda for the creation and settlement of families suffers from ups and downs, as well as the need for new research that assesses whether the objectives of the Agrarian Reform Policy reached those established in the legislation that regulates and legitimizes this policy since its implementation.
\end{abstract}

Keywords: Public Policy, Agrarian Reform, Indicators, Settlement Projects.

\section{POLIITICA PÚBLICA Y REFORMA AGRARIA: UN ANÁLISIS DE LOS PRINCIPALES INDICADORES DE LA POLÍTICA DE ASENTAMIENTO RURAL}

\begin{abstract}
Resumen
El presente artículo presenta los resultados de los principales indicadores de la Política de Reforma Agraria, desde su implementación en la década de 1970 hasta 2017. La metodología adoptada fue el estudio de caso, con la encuesta de datos de las propiedades rurales obtenidos para fines de creación de Proyectos de Liquidación, Familias de Liquidación y Supervisión Ocupacional de estos proyectos. Los resultados muestran que con cada cambio de gobierno, la agenda política para la creación y el asentamiento de las familias sufre de altibajos, así como la necesidad de nuevas investigaciones que evalúen si los objetivos de la Política de Reforma Agraria alcanzaron los establecidos en el Legislación que regula y legitima esta política desde su implementación.
\end{abstract}

Palabras clave: Política Pública, Reforma Agraria, Indicadores, Proyectos de Liquidación. 